\title{
A contribuição das atividades de base agropecuária na geração de emprego nos municípios de Mato Grosso do Sul (Brasil)
}

Marcio Coutinho. Investigador independente, Campo Grande, Brasil.

Mayra Bitencourt. Universidade Federal de Mato Grosso do Sul, Campo Grande, Brasil.

Leonardo Figueiredo-Neto. Universidade Federal de Mato Grosso do Sul, Campo Grande, Brasil.

Adriano Figueiredo. Universidade Federal de Mato Grosso do Sul, Campo Grande, Brasil.

RESUmo | O objetivo deste estudo foi analisar a contribuição das atividades de base agropecuária na geração de emprego formal. É de suma importância para avaliar o desenvolvimento territorial nos municípios do Estado de Mato Grosso do Sul. Utilizou-se o método quantitativo com a aplicação do Índice de Concentração Normalizado (ICN). Concluiu-se que as principais atividades econômicas geradoras de emprego estão relacionadas à administração pública, serviços e comércio, com participação relativa do total de empregos gerados no estado (19\%, 15\% e 9\%), em 2015. Foi comprovado que as atividades de base agropecuária contribuíram na geração de emprego (12\%) e 33 municípios do Estado, em um universo de 79, possuem especialização em, pelo menos, uma atividade de base agropecuária. As atividades de base agropecuária, além de gerarem emprego, contribuem direta e indiretamente para a dinamização de outros setores, constituindo-se, portanto, como peça-chave no desenvolvimento regional.

PALAVRAS-CHAVE | desenvolvimento regional e local, economia regional, desigualdades regionais.

ABSTRACT | The objective of this study was to analyze the contribution of agricultural-based activities to the generation of formal employment, a very important factor for evaluating territorial development in the municipalities of the State of Mato Grosso do Sul. A quantitative method was used with the application of the Normalized Concentration Index (ICN). The results showed that the main economic activities that generate employment are related to public administration, services and commerce, with a relative share of the total number of jobs generated in the state (19\%, 15\% and 9\%) in 2015. We found that agricultural-based activities contributed to the generation of employment (12\%), and that 33 state municipalities, in a universe of 79 , have specialization in at least one agricultural-based activity. The agricultural-based activities, in addition to generating employment, contribute directly and indirectly to the revitalization of other sectors, constituting, therefore, a key element in regional development.

KEYWORDS | regional development, regional economy, regional inequalities.

Recebido em 30 de maio de 2017, aprovado em 19 de março de 2018.

E-mails: M. Coutinho, coutinhomrc@gmail.com | M. Bitencourt, mayra.bitencourt@ufms.br | L. Figueiredo-Neto, leonardo.neto@ufms.br A.M.R. Figueiredo, adriano.figueiredo@ufms.br 


\section{Introduçáo}

A expressão "desenvolvimento" vem sendo utilizado nas mais diversas áreas do conhecimento e o seu conceito se apresenta em construçáo baseado em três modelos: associado ao crescimento econômico, como satisfação das necessidades básicas e, o terceiro e nem por isso menos importante, aquele que atua como elemento de sustentabilidade socioambiental (Santos, Braga, Santos \& Braga, 2012). Apesar de serem distintos, há uma relação entre eles, uma vez que essas bases nos remetem a pensar em uma evolução dos diversos agentes econômicos (população, empresas, estado etc.), nos mais variados aspectos (econômico, social, cultural etc.).

$\mathrm{Na}$ última década, observou-se que o Brasil passou por grande instabilidade econômica. O período entre 2006 a 2016 evidenciou que a maior taxa de crescimento do Рів foi em 2010, 7,5\%. A partir de então, ocorreram sucessivas quedas, chegando a uma taxa negativa de 3,8\%, em 2015. A inflação anual de 2006, mensurada pelo Índice de Preços ao Consumidor Amplo (IPCA), era de 3,14\% e, em 2015, subiu consideravelmente alcançando o patamar de 10,67\%. A taxa Selic encerrou, o ano de 2015 , cotada em $14,25 \%$, sendo que ela já foi praticada a $7,25 \%$, em novembro de 2012. Quanto aos indicadores sociais, observou-se que o nível de desemprego, que, na média do ano de 2015, foi de $7 \%$; no ano de 2016, já alcançou o nível de $11,8 \%$, representando algo em torno de 12 milhóes de pessoas desempregadas pertencentes à população economicamente ativa (Instituto Brasileiro de Geografia e Estatística, 2016).

Os indicadores mencionados não são os únicos capazes de mensurar o andamento das atividades econômicas. $\mathrm{Na}$ realidade, fazem parte de uma série de outros indicadores (balança comercial, nível de atividade econômica etc.) e fatores (sociais, políticos, culturais etc.) que contribuem para o entendimento de como está se desenvolvendo ou não, determinada economia, e foram aqui utilizados para realçar as consequências causadas por uma recessão econômica, principalmente no que tange à geração de emprego. Cabe salientar que, em uma economia capitalista, como é o caso da economia brasileira, a variável emprego tem grande importância para o funcionamento do sistema mencionado (Pochmann, 2002).

Nesse sentido, para que as políticas públicas sejam implementadas e obtenham sucesso, as especificidades do território precisam ser conhecidas para tornar possível a geração de efeitos positivos sobre o crescimento e desenvolvimento (Ortega, 2008).

Neste estudo, o crescimento está associado à elevação da produção de determinada regiáo e desenvolvimento implica na mudança de estruturas econômicas, sociais, políticas e institucionais, com melhoria da produtividade e da renda média da população. Constitui, portanto, um avanço no bem-estar da populaçáo. Outro conceito que este trabalho aborda relaciona-se com o desenvolvimento territorial, que Schneider (2004) define como um processo intrinsecamente territorial, podendo ser local ou regional. Ainda no entendimento desse teórico, o desenvolvimento territorial ocorre a partir do momento em que tais territórios tornam-se capazes de organizar os fatores endógenos, canalizando-os para o engrandecimento e solidificação da organização social, para o aumento da autonomia nas tomadas 
de decisóes dos agentes locais, para a capacidade de reter e reinvestir capitais em âmbito local, ou seja, para promover a inclusão social.

Com base nos dados do Ministério do Trabalho (мт), extraídos da Relação Anual de Informaçôes Sociais (RAIs), período de 2015, do total de empregos formais existentes no Brasil, 19,14\% estão alocados no segmento da administração pública. Situação semelhante ocorre no estado de Mato Grosso do Sul, onde, no mesmo período, o estoque de emprego era de 645.620 e a administração pública representava, aproximadamente, $20,12 \%$ do total.

Dentre os vários efeitos gerados pelo crescimento ou desenvolvimento na economia sul-mato-grossense, este estudo estabeleceu como objetivo analisar a contribuição das atividades de base agropecuária na geração de emprego formal nos municípios de Mato Grosso do Sul, com base nos dados secundários da RAIs, no período de 2006 a 2015. Este estudo trabalhou com dados secundários da geração de emprego e massa salarial obtidos por meio da Relação Anual de Informaçóes Sociais (RAIs), vinculada ao Ministério do Trabalho e Previdência Social. Optou-se pelo Índice de Concentração Normalizado (ICN) em função de esse indicador ser mais preciso, e por ele corrigir eventuais distorçóes advindas de outros indicadores (como o quociente locacional), devido ao tamanho ou concentraçáo das atividades.

Vale comentar que a presente pesquisa tem um caráter inédito para o estado de Mato Grosso do Sul, e seus resultados contribuirão para futuras tomadas de decisão, seja na esfera pública ou privada, no sentido de fomentar o desenvolvimento regional.

\section{Revisão da literatura}

Convém pontuar que, para muitos autores, crescimento e desenvolvimento são sinônimos. Souza (2009), por exemplo, pontua que o primeiro está associado à elevação da produção de determinada região e, o segundo implica na mudança de estruturas econômicas, sociais, políticas e institucionais, com melhoria da produtividade e da renda média da população. Constitui, portanto, um avanço no bem-estar da população.

A discussão sobre o desenvolvimento territorial, também entendida como economia regional, está apoiada e dividida em dois grandes blocos teóricos. O primeiro, relacionado ao conjunto de teorias clássicas de localização, evoluiu de forma, mais ou menos contínua, da publicação de Thünen (1966) e Isard (1956). No segundo bloco, encontra-se o conjunto de teorias de desenvolvimento regional com ênfase nos fatores de aglomeração, inspirados em Marshall e Keynes e tendo como principais expoentes Perroux, Myrdal, Hirschman e North (Monastério \& Cavalcante, 2011).

O modelo de Thünen (1826) parte do pressuposto de que os agentes são tomadores de preço (não existindo, dessa forma, o poder de monopólio). A produção é feita com retornos constantes de escala e coeficientes fixos de produção, o terreno é homogêneo, podendo ocorrer a livre entrada nas atividades agrícolas e os preços de cada produto são dados na cidade. A lógica do modelo é determinar, mediante formulação matemática, o ponto de maximização da renda da terra em diferentes localizaçôes, onde os custos de transportes são considerados. Ou seja, a distância 
entre o local de produção e o centro consumidor passa a ser um fator importante nesse processo dando original aos círculos ou anéis de Thünen.

Alfred Weber (1868-1958) defende que três fatores interferem na decisão da firma quanto à localização de atividades industriais: o custo de transporte, o custo da mão de obra e fatores de aglomeração ou desaglomeração (Weber, 1957). As empresas buscam se posicionar geograficamente para que os custos de transporte, tanto de matéria-prima quanto dos produtos finais, sejam o mínimo possível. No fator relacionado à mão de obra, Weber assume que ela não teria mobilidade espacial e que, com os custos reduzidos com esse fator, compensariam outros maiores com o transporte, sendo que a opção de instalaçáo das indústrias seria nas regióes onde o ônus fosse inferior (Cavalcante, 2008).

Walter Christaller (1893-1969) citado por Cruz (2000), na busca pela compreensão e explicação do tamanho, do número e da distribuição de cidades, estende a análise para os "lugares centrais" que distribuiriam bens e serviços para a região em seu entorno. Observa-se que a distância entre os consumidores e o produto final é um fator que pode determinar a produção ou não de determinado bem ou serviço. Christaller (citado por Cruz, 2000, p. 55) estabeleceu uma hierarquia entre as cidades, em que a produção de bens e serviços resultaria de "uma escala de produção que alcança um ótimo representado por uma demanda dividida em um espaço homogêneo".

Obedecendo à ordem cronológica, a contribuição de Isard foi no sentido de realizar uma síntese das teorias da escola clássica de localizaçáo percebendo, assim, a necessidade de incorporar nessa análise novas disciplinas e conclui com a proposta de criar a Regional Science, a qual seria uma nova linha de pensamento sobre o assunto (Monastério \& Cavalcante, 2011). Diante dessa abordagem, novos fatores de localização foram estudados, com o intuito de adequar a teoria com a realidade, como foi a obra de Motta (1960) que define cinco fatores de localização industrial: 1) orientação para as matérias-primas; 2) orientação para o mercado; 3) orientação para a mão de obra; 4) orientação para a energia e 5) orientação não especificamente definida.

Outra vertente ligada ao desenvolvimento regional ou territorial é aquela que enfatiza os fatores de aglomeração. A análise das aglomeraçóes produtivas, realizada por Marshall (1982), identifica como uma vantagem a economia de escala para a firma, como também as externalidades positivas decorrentes das relaçóes entre os diversos agentes econômicos, no caso, as empresas que estão próximas umas das outras. Krugman (1998, p. 50) ressalta que, além da economia da eficiência de escala no fornecimento de insumos, proporcionado por um grande mercado local, outros benefícios seriam: “[...] uma oferta abundante de mão de obra” e também a "[...] possibilidade de troca de informaçôes que ocorre quando empresas do mesmo setor se situam próximas umas das outras".

É na década de 1950 que surgem os grandes expoentes da teoria do desenvolvimento com ênfase nas aglomeraçóes. Vale destacar que o trabalho de Perroux (1977) resultou do estudo das relaçóes entre indústrias denominadas motrizes, aquelas que conseguem fazer com que o faturamento de produtos e serviços de outras sejam aumentados, e movidas as que têm seu faturamento aumentado em função das 
indústrias motrizes. Nesse sentido, para Perroux (1977, p. 146), o crescimento não "ocorre de forma homogênea, mas manifesta-se em pontos ou polos de crescimento, com intensidades variáveis, expandindo-se por diversos canais e com efeitos finais variáveis sobre toda a economia”.

O desenvolvimento regional seria induzido pelas indústrias motrizes por meio das seguintes formas de polarização: técnica, econômica, psicológica e geográfica. A polarização técnica refere-se aos efeitos positivos da relação entre as indústrias motrizes e outras empresas. $\mathrm{O}$ aspecto econômico diz respeito à geração de emprego e renda em função da instalação da indústria motriz. A polarização psicológica está atrelada ao clima favorável de sucesso obtido pela indústria motriz devido ao investimento realizado. A última forma seria a polarização geográfica, associada ao impacto que a indústria motriz causa no desenvolvimento das cidades, proporcionando uma redução dos custos de transporte e a criaçáo de economias externas e de aglomeração (Perroux, 1977).

Outro teórico que contribuiu para a evolução do pensamento econômico regional foi Myrdal, com a teoria da causaçáo circular e acumulativa. Ele afirmou que o crescimento das economias regionais tenderia a divergir ao longo do tempo. Todavia, para entender o modelo de Myrdal, convém partir do pressuposto que uma determinada região se desenvolve por um motivo eventual. A partir desse momento, aconteceria um despertar dos agentes econômicos que procurariam ali se instalar, em muitas situaçóes, oriundas de outras regióes, ampliando dessa maneira, o mercado de maneira geral, o que poderia contribuir para a geração de mais recursos, os quais tenderiam a serem reinvestidos. Assim, essa região dinâmica atrairia o trabalho, o capital e o espírito empreendedor de outras regióes, fortalecendo ainda mais a sua posição de destaque diante de outras, o que contribuiria para a ampliação das desigualdades regionais (Monastério \& Cavalcante, 2011).

Nesse cenário, encontra-se o estado de Mato Grosso do Sul, cuja identidade econômica está fortemente voltada para as atividades de base agropecuária, principalmente na produção de grãos e carne, com elevados índices de qualidade, reconhecidos internacionalmente (Brasil, 2003). A qualidade da terra existente no Estado, o clima favorável, a abundância de água, associados ao uso intensivo de tecnologia no campo, e os investimentos realizados tanto pelo setor público quanto privado, no sentido de melhoria de infraestrutura, para o escoamento da produçáo, contribuem para que o setor apresente grande produtividade (Empresa Brasileira de Pesquisa Agropecuária [Embrapa], 2008; Mato Grosso do Sul, 2015).

O Estado tem uma área de, aproximadamente, 36 milhóes de hectares e está dividido em 79 municípios, sendo que o pantanal ocupa um total 8,9 milhóes de hectares e, nessa região, há predominância de criação extensiva em pastagens nativas (Bungenstab, 2012). Soma-se isso ao fato de que a principal área econômica do Estado é a bacia do Paraná, que desfruta de solo favorável para o plantio florestal, além de possuir eficientes meios de transporte e estar posicionada geograficamente mais próxima dos mercados consumidores da região Sudeste (Mato Grosso do Sul, 2015). Os produtos nos quais ms se destaca são soja, milho e carne bovina, estando entre os maiores produtos nacionais, além da cana-de-açúcar e floresta cuja produçáo anual tem aumentado, colocando o Estado em posiçáo de destaque no 
cenário brasileiro (Bungenstab, 2012). Ms tem, também, o quarto maior rebanho bovino efetivo brasileiro, com 21 milhóes de cabeças, representando 9,89\% do rebanho nacional. Desse total, aproximadamente, 3,9 milhóes de cabeças têm o mercado nacional como seu principal destino (Instituto Brasileiro de Geografia e Estatística [IBGE], 2014).

As exportações do agronegócio do estado de ms foram de US\$4,4 bilhóes, em 2015 , sendo que a carne bovina representou $11 \%$ e os principais países de destino foram Hong Kong, Rússia e Egito (Ministério da Agricultura, Pecuária e Abastecimento [MAPA], 2016). Ainda no comércio exterior, o volume de receitas proporcionadas pelas exportaçóes de MS, no primeiro quadrimestre de 2016, atingiu o montante de US $\$ 1,6$ bi (FОв) e os cinco principais produtos foram: soja, respondendo por $33,4 \%$, do total das exportaçóes; celulose com 22,40\%, milho representando 12,07\%; carne com 5,68\% e açúcares de cana com participação de 4,51\% (Ministério do Desenvolvimento, Indústria e Comércio Exterior [MDIC], 2016)

Procurando diversificar sua matriz econômica, o Estado vem desenvolvendo açóes no sentido de atrair indústrias e promover o turismo, sobretudo devido às riquezas naturais, em especial, o pantanal, considerado patrimônio natural de valor inestimável (Brasil, 2003). O pIB do estado do Ms, em 2013, foi estimado em R\$ 69,1 bilhôes (IBGE, 2016), sendo que o setor primário e a indústria de transformação representaram 37\% de toda a riqueza (Secretaria de Estado de Meio Ambiente e Desenvolvimento Econômico [SEMADE], 2015).

No que tange à qualidade de vida, mensurada por meio do Índice de Desenvolvimento Humano Municipal (IDHM), verificou-se melhora a cada década. Em 1991, dos 78 municípios de MS, 70 apresentavam indicador considerado muito baixo (inferior a 0,499) e, em 2010, apenas 4 apresentavam índice baixo (entre 05 a 0,599) e 27 municípios apresentaram índice alto (entre 0,7 a 0,799) (IBGE, 2015).

Os números mostram que ocorreram mudanças significativas no estado, seja no aspecto social seja no econômico. A populaçáo que era de 1,3 milhóes de residentes, em 1980, passou a 2,4 milhóes, em 2010, e, atualmente, apresenta uma taxa de urbanização de 85\%, contra 67\%, em 1980 (sEmade, 2015). Em 2005, o PIB era de, aproximadamente, R\$ 21 bilhóes e foi estimado, para o ano de 2013, no valor de R $\$ 69$ bilhóes (sEMAde, 2016).

No ano de 2010, nenhum município do estado de Ms apresentava indicador do IDHM muito baixo (IBGE, 2015), a quantidade de municípios aumentou em uma unidade. Embora o binômio soja/boi seja representativo para a economia do Estado, outros produtos começam a se destacar, como o caso da cana-de-açúcar, da celulose e do milho, que atraem outros agentes econômicos de cada cadeia produtiva, contribuindo para o desenvolvimento territorial e na geraçáo de empregos para essa população.

Essas diversificaçóes das atividades econômicas resultaram da Política de Desenvolvimento Regional do estado de Mato Grosso do Sul (PDR - Ms, 2010 - 2030) (Mato Grosso do Sul, 2015), elaborada em 2009, alinhada com a Política Nacional de Desenvolvimento Regional, que tinha como objetivo a redução das desigualdades do nível de vida da população, além de outras políticas públicas. Essa situação poderá ser confirmada ou não, por ocasião da avaliação das políticas e suas 
contribuiçóes para a o incremento de outras atividades econômicas e, consequentemente, a geração de emprego e renda, respondendo, assim, às pretensóes desta pesquisa.

\section{Metodologia}

Face aos objetivos, esta pesquisa utilizou a abordagem quantitativa com caráter de análise descritiva com base em fontes secundárias, obtidas por meio de registros do IBGE (Instituto Brasileiro de Geografia e Estatística) e Ministério do Trabalho (MTE). Acrescenta-se, ainda, que a análise da pesquisa se deu mediante procedimentos estatísticos, comparados aos resultados obtidos.

De posse dos dados, foi realizado o perfil econômico do estado de Mato Grosso do Sul em dois momentos distintos, 2006 e 2015, identificando a evolução e diversificação das atividades econômicas. Isso permitiu entender melhor a efetiva contribuição das atividades de base agropecuária para a geração de emprego.

Os procedimentos metodológicos foram realizados e divididos em etapas. $\mathrm{Na}$ primeira, foram coletados os dados da RAIs referentes à quantidade de emprego das diversas atividades econômicas, no período de 2006 a 2015, em todos os municípios de Ms.

Para a identificação das atividades econômicas e realização da coleta de dados, foi utilizada a subclasse das seçóes A (agropecuária) e C (indústria de transformação) do código de Classificaçáo Nacional de Atividade Econômica (CNAE) 2.0.

A segunda etapa consistiu em calcular a participação relativa de cada atividade econômica em relaçáo ao total das atividades econômicas existentes no estado do Mato Grosso do Sul. O cálculo da Participação relativa (PR) foi realizado através da seguinte equação:

$$
P R=\frac{E_{M S}^{i}}{E_{M S}}(1)
$$

Onde:

$E_{M S}^{i}$ é o emprego da atividade "i" de todo o estado de MS

$E_{M S}$ é o emprego de todas as atividades do estado de MS.

A partir dos dados obtidos, realizou-se um ranking de ordem decrescente das atividades econômicas, objetivando, assim, avaliar quais atividades são mais importantes na geração de emprego para o estado de Mato Grosso do Sul. Foram inseridas, nesse ranking, somente atividades com participação relativa igual ou superior a $0,5 \%$. A partir desses procedimentos, foram identificadas as atividades econômicas de base agropecuária que mais geram empregos no estado de Ms.

Após a avaliação das atividades econômicas de base agropecuária representativas, na geraçáo de emprego e renda, para o estado de MS, foi calculado o Índice de Concentraçáo Normalizado (ICN), mediante cálculo de análise multivariada de dados e Análise de Componentes Principais (ACP). 
O Índice de Concentração Normalizado (ICN) foi a metodologia empregada para determinar em qual a atividade econômica o município é especializado. Esse indicador compóe-se por três componentes, a saber: QL - quociente locacional; HHm - Hirschman-Herfindahl modificado e PR - participação relativa.

$\mathrm{O}$ primeiro componente ( $\mathrm{QL}$ - quociente locacional) procurou mensurar a primeira característica de um aglomerado, ou seja, a especificidade de uma atividade dentro de uma região. Britto e Albuquerque (2002), Sebrae (2002), IEDi (2002) e Suzigan et al. (2003) propuseram metodologias para a identificação de aglomeraçóes produtivas, atribuindo ao Quociente Locacional (QL) um papel importante para observar se determinado município possui especialização em uma atividade específica.

$\mathrm{O}$ QL comparou duas estruturas econômicas. Essa comparação se dá por meio da razão entre a "economia em estudo" (numerador) e a "economia em referência" (denominador). O cálculo é realizado através da seguinte fórmula:

$$
Q L=\frac{E_{j}^{i} / E_{j}}{E_{M S}^{i} / E_{M S}}(2)
$$

Onde:

$E_{j}^{i}$ Emprego do setor "i” no município “j”;

$E_{M S}^{i}$ Emprego em todos os setores do município “j”; Emprego do setor “i” no estado de Mato Grosso do Sul; e,

$E_{M S}$ Emprego em todos os setores do estado de Mato Grosso do Sul.

Crocco, Galinari, Santos, Lemos e Simóes (2006) ressaltaram, quando da utilização do QL, dois pontos importantes, sendo que o quociente "[...] deve ser utilizado com cautela, visto que a interpretação de seu resultado deve levar em conta as características da economia em que está sendo considerada como referência”, e o segundo aspecto menciona que, para as regiôes de porte médio, esse indicador é ideal. O QL pode causar distorçôes em função de regiôes pequenas e com estrutura produtiva pouco diversificada, causando uma sobrevalorização do peso do setor para a regiâo, ou subvalorização da importância de setores em regiôes com estrutura produtiva bem diversificada. Para reduzir o impacto desse problema, foi elaborado um segundo componente: o HHm - Hirschman-Herfindahl, modificado para poder captar o real significado do peso da atividade na estrutura produtiva local, permitindo, assim, a comparação do peso da atividade i do município $\mathrm{j}$ na atividade i do Estado com o peso da estrutura produtiva do município $\mathrm{j}$ na estrutura do Estado. A fórmula de cálculo é como em (3), com as variáveis como definidas anteriormente.

$$
H H m=\left(\frac{E_{j}^{i}}{E^{i}}\right)-\left(\frac{E_{j}}{E_{M S}}\right)
$$

Para identificar a importância da atividade do município em relação ao Estado, foi utilizado o terceiro componente, denominado PR - Participação relativa, obtido através da seguinte fórmula: 


$$
P R=\frac{E_{j}^{i}}{E_{M S}}(4)
$$

O PR indica a participação relativa do emprego do setor i no município j em relação ao total de emprego de todos os setores do estado do MS. O ICN é obtido pela combinaçáo linear dos componentes padronizados, que podem apresentar distinta capacidade de representar as forças aglomerativas, aliando aos pesos específicos de cada um dos componentes, como segue:

$$
I C n=\theta_{1} Q L_{i j}+\theta_{2} H H m_{i j}+\theta_{3} P R_{i j}(5)
$$

A análise de componentes principais utilizou um método multivariado para a obtenção dos pesos de cada um dos componentes $\theta \mathrm{i}$.

\section{A técnica da análise multivariada - Análise de componentes principais}

Segundo Mingoti (2005, p. 59), "seu principal objetivo é o de explicar a estrutura de variância e covariância de um vetor aleatório, composto de p-variável aleatório, através da construção de combinaçôes lineares das variáveis originais". Essas combinaçôes lineares são chamadas de componentes principais e são não correlacionadas entre si. Se temos p-variáveis originais, é possível obter-se p componentes principais. Portanto, a análise de componentes principais toma $\mathrm{p}$ variáveis $\mathrm{X} 1, \mathrm{X} 2, \ldots \mathrm{Xp}$ e encontra combinaçôes lineares dessas, produzindo os componentes $\mathrm{Z} 1, \mathrm{Z} 2, \ldots, \mathrm{Zp}$ :

$$
Z_{i}=a_{i 1} X_{1}+a_{i 2} X_{2}+\ldots+a_{i p} X_{p}(6)
$$

A matriz de covariância das variáveis é utilizada para encontrar as variâncias associadas a cada componente e também os coeficientes das combinaçóes lineares. As variâncias dos componentes principais são os autovalores dessa matriz, e os coeficientes são os autovetores associados. A matriz de variância é simétrica:

$$
C=\left[\begin{array}{cccc}
c_{11} & c_{12} & \cdots & c_{1 p} \\
c_{21} & c_{22} & \cdots & c_{2 p} \\
\vdots & \vdots & \vdots & \vdots \\
c_{p 1} & c_{p 2} & \cdots & c_{p p}
\end{array}\right] \text { (7) }
$$

A soma dos autovalores é igual à soma dos elementos da diagonal principal da matriz de covariância, ou seja, ao traço dessa matriz:

$$
\lambda_{1}+\lambda_{2}+\ldots \lambda_{p}=c_{11}+c_{22}+\ldots+c_{p p}(8)
$$

Uma vez que cii é a variância de $\mathrm{Xi}$, e $\lambda \mathrm{i}$ a dos $\mathrm{Zi}$, tem-se que a soma das variâncias de todas as variáveis originais é igual à de todos os componentes.

Portanto, pode-se garantir que o conjunto de todos os componentes leva em consideração a variação total dos dados. 
Com o resultado obtido, foi realizada a análise de componentes principais (por meio de software estatístico, como o Stata), e os resultados encontrados, inicialmente, como a matriz de coeficientes e a variância dos componentes, serviram de base para a determinação do peso de cada componente. Inicialmente, é importante a apresentação dos autovalores ou variância dos 3 componentes principais (tabela 1).

TAbela I | Os autovalores da Matriz de Correlação ou Variância Explicada pelos Componentes Principais

\begin{tabular}{|c|c|c|}
\hline COMPONENTE & $\begin{array}{c}\text { VARIÂNCIA EXPLICADA } \\
\text { PELO COMPONENTE }\end{array}$ & \multicolumn{1}{|c|}{ VARIÂNCIA EXPLICADA TOTAL } \\
\hline 1 & $\beta 1$ & $\beta 1$ \\
\hline 2 & $\beta 2$ & $\beta 1+\beta 2$ \\
\hline 3 & $\beta 3$ & $\beta 1+\beta 2+\beta 3(=100 \%)$ \\
\hline
\end{tabular}

FONTE CROCCO ET AL., 2006

A tabela 2 mostra a matriz de coeficientes ou os autovetores da matriz de correlação. Por meio dela, é possível calcular qual a participação relativa de cada um dos indicadores em cada um dos componentes e, dessa forma, entender a importância das variáveis nos componentes.

Tabela 2 | Matriz de Coeficientes ou Autovetores da Matriz de Correlação

\begin{tabular}{|c|c|c|c|}
\hline INDICADOR INSUMO & COMPONENTE I & COMPONENTE 2 & COMPONENTE 3 \\
\hline 1 & $\alpha 11$ & $\alpha 12$ & $\alpha 13$ \\
\hline 2 & $\alpha 21$ & $\alpha 22$ & $\alpha 23$ \\
\hline 3 & $\alpha 31$ & $\alpha 32$ & $\alpha 33$ \\
\hline
\end{tabular}

FONTE CROCCO ET AL., 2006

Efetua-se, para tanto, a soma da função módulo dos autovetores associados a cada componente, onde se obtêm os $\mathrm{Ci}$, e, em seguida, divide-se o módulo de cada autovetor pela soma (Ci) associada aos componentes, como mostra a tabela 3, que apresenta os autovetores recalculados ou a participação relativa de cada índice nos componentes.

tabela 3 | Matriz de Autovetores Recalculados ou Participação relativa dos Indicadores em cada componente

\begin{tabular}{|c|c|c|c|}
\hline INDICADOR & COMPONENTE I & COMPONENTE 2 & COMPONENTE 3 \\
\hline $\mathrm{qL}$ & $\alpha_{11}^{\prime}=\frac{\alpha_{11}}{C_{1}}$ & $\alpha_{12}^{\prime}=\frac{\alpha_{12}}{C_{2}}$ & $\alpha_{13}^{\prime}=\frac{\alpha_{13}}{C_{3}}$ \\
\hline PR & $\alpha_{21}^{\prime}=\frac{\alpha_{21}}{C_{1}}$ & $\alpha_{22}^{\prime}=\frac{\alpha_{22}}{C_{2}}$ & $\alpha_{23}^{\prime}=\frac{\alpha_{23}}{C_{3}}$ \\
\hline $\mathrm{HHm}$ & $\alpha_{31}^{\prime}=\frac{\alpha_{31}}{C_{1}}$ & $\alpha_{32}^{\prime}=\frac{\alpha_{32}}{C_{2}}$ & $\alpha_{33}^{\prime}=\frac{\alpha_{33}}{C_{3}}$ \\
\hline
\end{tabular}

FONTE CROCCO ET AL., 2006 
Tendo em vista que os $\alpha^{\prime} \mathrm{ij}$ da tabela 3 representam o peso que cada variável assume dentro de cada componente e que os autovalores ( $\beta$ s da tabela 1 ) fornecem a variância dos dados associado ao componente, o peso inicial $\left(\theta^{\prime}\right)$ de cada indicador insumo é, entáo, o resultado da soma dos produtos dos $\alpha$ 'ij pelo seu autovalor correspondente, para cada componente.

$$
\begin{aligned}
& \theta_{1}^{\prime}=\alpha_{11}^{\prime} \beta_{1}+\alpha_{12}^{\prime} \beta_{2}+\alpha_{13}^{\prime} \beta_{3} \\
& \theta_{2}^{\prime}=\alpha_{21}^{\prime} \beta_{1}+\alpha_{22}^{\prime} \beta_{2}+\alpha_{23}^{\prime} \beta_{3} \\
& \theta_{3}^{\prime}=\alpha_{31}^{\prime} \beta_{1}+\alpha_{32}^{\prime} \beta_{2}+\alpha_{33}^{\prime} \beta_{3}
\end{aligned}
$$

Onde:

$\alpha$ 'são os autovetores recalculados e os $\beta$ s são as variâncias explicadas por cada componente.

A partir da obtenção dos componentes e seus respectivos pesos, utiliza-se a equação (5) para a determinação do índice de concentração normalizado. ICN > 1, que indica que a atividade estudada naquela regiáo, ou município, tem papel de destaque na estrutura econômica, ou seja, o município é especializado naquela atividade.

\section{Resultados}

Tradicionalmente, a economia se divide em três grandes setores econômicos: primário, secundário e terciário. Isso posto e para identificar e entender a dinâmica da geração de emprego formal, convém uma primeira aproximação sobre esses setores, que, por sua vez, foram divididos em oito grandes grupos de atividades econômicas, como mostrado na tabela 4, que espelha o estoque formal de empregos do Ms e as respectivas participaçóes de cada grupo em relação ao total, em dois momentos: 2006 e 2015 . Convém frisar que o aumento no estoque de emprego é uma consequência natural do crescimento da economia, porém um fator a ser destacado é o comportamento dessa variável em relação ao movimento de admissão e demissão e, por resultante, o saldo de empregos existentes em cada atividade econômica.

Observa-se na tabela 5, dois momentos distintos. O primeiro, em 2006, revela o período de crescimento econômico de Mato Grosso do Sul, quando o saldo de empregos formais naquele ano foi de 6.507 , em contraste com o segundo período (2015), quando o nível de demissóes superou o de admissóes em 11.813, devido à recessão que se instalou em todo o território nacional, a partir de 2014. 
TABELA 4 Estoque de emprego formal por grupos de atividades econômicas no MS em 2006 e 2015

\begin{tabular}{|l|r|r|r|c|}
\hline \multirow{2}{*}{\multicolumn{1}{c|}{ ATIVIDADES ECONÔMICAS }} & \multicolumn{2}{c|}{ 20I 5 } & \multicolumn{2}{c|}{2006} \\
\cline { 2 - 5 } & ESTOQUE & $\begin{array}{c}\text { PART. } \\
\text { TOTAL \% }\end{array}$ & ESTOQUE & $\begin{array}{c}\text { PART. } \\
\text { TOTAL \% }\end{array}$ \\
\hline Extração Mineral & 2.463 & 0,38 & 1.601 & 0,36 \\
\hline Indústria Transformação & 91.871 & 14,23 & 53.141 & 12,11 \\
\hline Serviço Industrial de Utilidade Pública & 5.769 & 0,89 & 3.023 & 0,69 \\
\hline Construção civil & 25.032 & 3,88 & 14.525 & 3,31 \\
\hline Comércio & 127.470 & 19,75 & 81.729 & 18,63 \\
\hline Serviços & 193.650 & 30,00 & 108.678 & 24,77 \\
\hline Administração Pública & 129.957 & 20,13 & 118.264 & 26,96 \\
\hline Agropecuária & 69.308 & 10,74 & 57.724 & 13,16 \\
\hline Total & 645.520 & & 438.685 & \\
\hline
\end{tabular}

FONTE MTE - CADASTRO GERAL DOS EMPREGADOS E DESEMPREGADOS

TABEla 5 Evolução do emprego formal por grupo de atividades econômicas no MS

\begin{tabular}{|c|c|c|c|c|c|c|}
\hline \multirow{2}{*}{$\begin{array}{l}\text { ATIVIDADE } \\
\text { ECONÔMICA }\end{array}$} & \multicolumn{3}{|c|}{2015} & \multicolumn{3}{|c|}{2006} \\
\hline & ADMISSÃO & DEMISSÃO & SALDO & ADMISSÃo & DEMISSÃO & SALDO \\
\hline Extração Mineral & 589 & 794 & -205 & 495 & 393 & 102 \\
\hline Industria Transformação & 43.396 & 49.366 & -5.970 & 33.278 & 29.888 & 3.390 \\
\hline SIUP & 1.844 & 1.696 & 148 & 653 & 668 & -15 \\
\hline Construção civil & 24.804 & 28.020 & -3.216 & 16.441 & 15.229 & 1.212 \\
\hline Comércio & 69.857 & 72.112 & -2.255 & 36.726 & 35.135 & 1.591 \\
\hline Serviços & 92.736 & 94.905 & -2.169 & 46.334 & 44.643 & 1.691 \\
\hline Administração Pública & 85 & 92 & -7 & 724 & 2.034 & -1.310 \\
\hline Agropecuária & 38.355 & 36.494 & 1.861 & 36.011 & 36.165 & -154 \\
\hline Total & 271.666 & 283.479 & -11.813 & 170.662 & 164.155 & 6.507 \\
\hline
\end{tabular}

FONTE MTE - CADASTRO GERAL DOS EMPREGADOS E DESEMPREGADOS

Considerando a variável emprego, no ano de 2006, as atividades econômicas específicas de base agropecuária eram detentoras de um estoque de 22.077 postos de trabalhos ocupados, representando 5,83\% de todo o estado de Ms. As atividades econômicas específicas e suas respectivas participação no mercado na geração de emprego são: i) frigorífico - abate de bovinos, com 3,55\%; ii) frigorífico - abate de aves, com 1,13\%; iii) frigorífico - abate de suínos, com 0,60\%; e iv) fábrica de álcool, com $0,55 \%$.

Com o passar do tempo, essa estrutura vai se modificando. Ao analisar os dados da geração de emprego de 2015, observa-se que a participação das atividades de base agropecuária, na geração de emprego no estado do ms, é de 15,45\%. Nesse ano, 
nove atividades econômicas específicas geraram 99.741 empregos. As atividades ligadas à bovinocultura, criação de bovinos e frigorífico - abate de bovinos constitui o carro chefe da geração de postos de trabalho, respondendo por 7,65\% do emprego gerado no Ms, sendo que a criaçáo de bovinos respondeu por $5,72 \%$ e o abate por $1,93 \%$. Outro setor que se destaca na economia de Ms, principalmente na geração de emprego, é o da cana-de-açúcar.

O conjunto de três atividades ligadas a esse setor, fabricação de álcool, fabricação de açúcar e cultivo da cana-de-açúcar, foram responsáveis pela geração de 25.116 empregos, ou seja, respondiam por 3,99\% do estoque de emprego no Ms.

Esta pesquisa revela que, apesar de a soja ser um produto importante para a economia tanto nacional como regional, principalmente no aspecto do comercio internacional, atividades ligadas a esse setor só começaram a ser representativas para os munícipios do Ms, na geração de emprego, apenas a partir de 2009, com a atividade econômica específica de cultivo de soja. A sojicultura empregava, em 2009, 4.919 pessoas, representando $0,94 \%$ de todo o estado e, em 2015, esse número saltou para 9.796 , com $1,52 \%$ de participação relativa no efetivo total do estado de ms. Tal fato pode ser justificado em função do aumento em, aproximadamente, $35,5 \%$ da área colhida, que, em 2010, era de 1.732.297ha, e a estimativa para 2015 foi de 2.348.973ha, demonstrando um crescimento expressivo (sEMADE, 2015).

A cultura de eucalipto se destacou na geração de emprego do Ms, em 2013, com 3.754 empregos criados. Em 2015, esse número se alterou para 4.551, representando $0,71 \%$ de todo o emprego gerado no Ms. Fazendo um ranking das atividades de base agropecuária, a cultura de eucalipto supera as atividades de abate de suínos (4.543 empregos e participação relativa de $0,70 \%$ ) e cultivo de cana-de-açúcar (4.192 empregos e participação relativa de 0,65\%). Esse aumento é justificado em função da instalação de duas plantas destinadas à fabricação de celulose.

Reforça-se que, como já observado em parágrafo anterior, são em número de nove as atividades econômicas específicas de base agropecuária que contribuem para a geração de emprego nos municípios de Ms, estando presente em 34 municípios: criação de bovinos, abate de bovinos, abate de aves, abate de suínos, fabricação de açúcar, fabricação de álcool, cultivo de soja, cultivo de eucaliptos, cultivo de cana-de-açúcar.

Inicia-se assim, a apresentação do resultado do ICN, abordando a atividade econômica específica, denominada criação de bovinos, a qual tem importante influência na geração de emprego para aos municípios de Ms, sendo que, nos 79 municípios, ela figura entre as 4 mais importantes. Entretanto, o grau de especialização na atividade econômica da bovinocultura, mensurado pelo ICN, revelou que 05 municípios apresentam essa característica (tabela 6).

Ou seja, para esses municípios, a atividade de criação de bovinos constitui fator de geração de emprego, embora existam outras atividades econômicas que geram mais empregos, como, a administração pública, cultivo de grãos, frigoríficos. 
TABELA 6 | ICN referente à atividade de criaçáo de bovino, no MS - 2015

\begin{tabular}{|l|c|l|c|}
\hline \multicolumn{1}{|c|}{ MUNICíPIO } & ICN & \multicolumn{1}{c|}{ MUNICÍPIO } & ICN \\
\hline Brasilândia & 1,08 & Ribas do Rio Pardo & 1,74 \\
\hline Corumbá & 1,16 & Santa Rita do Pardo & 1,27 \\
\hline Porto Murtinho & 1,49 & & \\
\hline
\end{tabular}

FONTE ELABORADO PELOS AUTORES, COM DADOS DA RAIS 20 I 5

A atividade econômica específica de abate de bovinos é de especialidade de 07 municípios (tabela 7), sendo que, para os municípios de Bataguassu e Rochedo, o grau de especialização nessa atividade foi mais alto, 3,49 e 2,50, respectivamente, em comparaçáo com os demais, indicando que, para esses municípios, a atividade de abate de bovinos é muito importante.

Os municípios mencionados são considerados de pequeno porte. De acordo com o censo de 2010, Bataguassu tinha pouco mais de 19 mil habitantes e, dos 6.015 empregos gerados em 2015, 26,40\% estavam alocados na atividade de abate de bovinos. Rochedo apresenta uma situação mais dependente dessa atividade. Com uma populaçáo de pouco mais de 5 mil habitantes e 1.224 empregos gerados, em 2015, a atividade em questão absorveu, aproximadamente, $44,50 \%$ do estoque de emprego. Ou seja, caso as indústrias frigoríficas deixem de atuar nesses municípios, a economia deles tende a ser impactada negativamente (IBGE; RAIS).

$\mathrm{Na}$ atividade de abate de aves, são cinco os municípios que têm especialização nessa atividade econômica, e estáo evidenciados na tabela 7, com destaque para os municípios de Sidrolândia e Itaquiraí. Esses municípios são considerados de pequeno porte, com populaçáo aproximada de 42 mil e 18 mil, respectivamente (IBGE), e a atividade econômica em pauta foi a que mais empregou nesses municípios, em 2015, representando 23,96\% do estoque de empregos, em Sidrolândia, e $39,07 \%$, em Itaquiraí (RAIS).

\section{TABELA 7 ICN referente à atividade de abate de bovino, aves e suínos no MS - 2015}

\begin{tabular}{|l|l|l|l|c|}
\hline \multicolumn{1}{|c|}{ ATIVIDADE } & \multicolumn{1}{|c|}{ MUNICÍPIO } & \multicolumn{1}{|c|}{ ICN } & \multicolumn{1}{c|}{ MUNICÍPIO } & ICN \\
\hline \multirow{3}{*}{ Abate de bovinos } & Anastácio & 1,28 & Naviraí & 1,78 \\
& Bataguassu & 3,49 & Nova Andradina & 1,85 \\
& Caarapó & 1,08 & Rochedo & 2,50 \\
& Cassilândia & 1,23 & & \\
\hline \multirow{3}{*}{ Abate de aves } & Aparecida do Taboado & 1,03 & Itaquirai & 5,13 \\
& Caarapó & 1,11 & Sidrolândia & 4,82 \\
\hline Abate de suínos & Dourados & 2,35 & & \\
\hline
\end{tabular}

FONTE ELABORADO PELOS AUTORES, COM DADOS DA RAIS 20 I 5 
A terceira atividade inserida no grupo de abate é a relacionada com os suínos. Os municípios especializados nessa área são Dourados $(\mathrm{ICN}=4,65)$ e São Gabriel do Oeste $(\mathrm{ICN}=6,18)$. O alto indicador revelado pelo ICN pode ser justificado em função de essa atividade (abate de suínos) representar 22,88\% do estoque de emprego existente em 2015, no município de São Gabriel do Oeste (ocupando a primeira posição no ranking das atividades que geram emprego). Para o município de Dourados, essa atividade ocupa a terceira posiçáo, respondendo por 4,06\% dos empregos gerados no ano em referência (RAIS).

Para Isard (1956), as organizaçóes se concentram dentro de uma região, formando as aglomeraçóes, o que possibilita a redução de custos nas relaçôes industriais. Entende-se, assim, o motivo das localizaçôes da maioria das indústrias frigoríficas que atuam basicamente com abate de bovinos. Suas plantas estão instaladas em municípios centrais, como Dourados e Campo Grande (apesar de essa última não apresentar especialização nessa atividade econômica), e também em locais que fazem divisas com outros estados, permanecendo, assim, próximo ao mercado produtor, além de se posicionar fisicamente de forma estratégica para o escoamento da produção, seja para atender ao mercado interno ou à demanda internacional.

As organizaçóes que atuam na atividade de abate de aves ou suínos procuram também estar geograficamente posicionadas de maneira a otimizar suas relaçóes com os diversos agentes econômicos locais, contribuindo para uma melhor produtividade e relação custo e benefício.

Entende-se, portanto, que a presença das indústrias relacionadas com o abate de bovinos, aves e suínos é importante para o desenvolvimento econômico regional, dinamizando o comércio e a economia local mediante geraçáo de empregos e salários, principalmente para os municípios de pequeno porte, com população inferior a 45 mil habitantes. Outro grupo de atividades econômicas está relacionado diretamente com a agricultura, que compóe o cultivo de soja, de cana-de-açúcar e o de eucalipto; os municípios especializados nessas culturas e seus respectivos ICNs, estão evidenciados na tabela 8 .

\section{TABELA 8 ICN referente à atividade do cultivo de soja, cana-de-açúcar e eucalipto em MS - 2015}

\begin{tabular}{|c|c|c|c|c|}
\hline ATIVIDADES & MUNICÍPIOS & ICN & MUNICÍPIOS & ICN \\
\hline \multirow{4}{*}{ Cultivo de Soja } & Aral Moreira & 1,16 & Ponta Porã & 1,20 \\
\hline & Chapadão do Sul & 1,59 & São Gabriel do Oeste & 1,03 \\
\hline & Laguna Carapã & 2,46 & Sidrolândia & 1,01 \\
\hline & Maracaju & 2,61 & Sonora & 4,32 \\
\hline \multirow{3}{*}{ Cultivo de cana-de-açúcar } & Aparecida do Taboado & 1,16 & Rio Brilhante & 1,62 \\
\hline & Caarapó & 3,50 & Vicentina & 2,60 \\
\hline & Costa Rica & 5,55 & & \\
\hline \multirow{2}{*}{ Cultivo de Eucalipto } & Agua Clara & 2,64 & Selvíria & 3,00 \\
\hline & Santa Rita do Pardo & 2,38 & Três Lagoas & 5,19 \\
\hline
\end{tabular}

FONTE ELABORADO PELOS AUTORES, COM DADOS DA RAIS 20 I 5 
O cultivo de soja é uma atividade consolidada no estado de ms, estando presente na regiáo desde o início dos anos 1970, sendo que seu produto representa uma importante parcela na balança comercial estadual (principal produto exportado pelo Ms, em 2016, representando, aproximadamente, 25\% do total das exportaçóes estaduais), contribuindo para a geração de empregos nos municípios de MS.

Reforçando o mencionado no início da apresentação dos resultados, a produção de soja referente à safra 2015/2016 foi de 7.241.400 toneladas, representando $7,59 \%$ da produção nacional e a produtividade média do Ms foi de $2.980 \mathrm{~kg} / \mathrm{ha}$, ficando superior à média nacional que foi de $2.870 \mathrm{~kg} / \mathrm{ha}$ (Companhia Nacional de Abastecimento [CONAB], 2015). Oito municípios apresentaram especialização nessa atividade, com destaque para Laguna Carapá, Maracaju e Sonora que apresentaram ICN de 2,46;2,61 e 4,32, respectivamente, caracterizando a importância dessa atividade na geração de empregos e salários para os referidos municípios. O cultivo de soja constitui a atividade que mais gerou empregos nos municípios de Sonora e Laguna Carapá, com uma representatividade de 32,88\% e 34,02\%, respectivamente, do estoque total de empregos daqueles municípios. Para Maracaju, esse percentual foi de $12,10 \%$, constituindo-se a terceira atividade mais importante.

Ao analisar a posição geográfica desses municípios, observa-se a concentraçáo dessa atividade na regiáo centro-sul do estado, formando um arco, que poderia ser denominado "corredor da soja" ou "aglomerado produtivo da sojicultora", que se inicia no município de Sidrolândia, descendo ao sul para as regiôes de Maracaju, Ponta Porá, Laguna Carapá. Concluindo esse "arco" com o município de Aral Moreira. Nesses aglomerados, o mercado consumidor e as fontes de matéria-prima podem não estar no mesmo espaço.

A tendência do processo produtivo é estar próximo à matéria-prima, enquanto os produtores de bens preferiráo a proximidade com o mercado consumidor. Essa é uma característica das economias dos municípios de pequeno porte, onde se concentra a fase inicial da produção. Hirschman (1961) citou que as regióes privilegiadas recebem maiores investimentos para a geração do desenvolvimento e, ao ocorrer uma concentração de atividade econômica, haverá maior nível de emprego e salário para a região. Consequentemente, aumentaráo o consumo e os investimentos.

O cultivo de cana-de-açúcar é outra atividade constante nesse grupo, há mais de 10 anos, no Ms, cuja participação vem crescendo na economia regional. Isso se destaca na quantidade da área plantada na safra 2015/26, que foi de 596 mil hectares contra 139 mil hectares, em 2005/2006 (CONAB). Essa nova situação tem reflexo direto no aumento de uso de fatores de produção, sobretudo no que diz respeito à utilização de máo de obra, fato que pode ser observado a partir de 2009, quando a quantidade de empregos gerados nessa atividade começa a ser representativa, respondendo por $1,64 \%$ do estoque de empregos.

Os municípios que possuem especialização na atividade econômica do cultivo de cana-de-açúcar, com os respectivos indicadores, estáo elencados na tabela 8 , com destaque para Caarapó e Costa Rica que apresentaram ICN de 3,50 e 5,55, respectivamente. Esses dois municípios têm a atividade econômica em pauta como a principal fonte de geração de emprego. Em Costa Rica, 24,37\% de todo o emprego 
gerado refere-se ao cultivo de cana e, no município de Caarapó, a atividade do cultivo de cana responde por $14,2 \%$ de todo o estoque de emprego.

A terceira e última atividade inserida nesse grupo é o cultivo de eucalipto e que, de acordo com o resultado da mensuração do ICN, revelou que os municípios que apresentam especialidade nessa atividade econômica estão evidenciados na tabela 8 . Exceto o município de Três Lagoas, com populaçáo superior a 100 mil habitantes e atividades econômicas diversificadas, os outros três quatro municípios são de pequeno porte (população inferior a 15 mil habitantes e atividades econômicas concentradas). O cultivo de eucalipto é a segunda maior geradora de emprego nos quatro municípios, sendo responsável por 16,99\% dos empregos gerados em Água Clara, por 22,02\% em Santa Rita do Pardo, 28,91\% em Selvíria, e 6,93\% em Três Lagoas.

Apesar de a atividade do cultivo de eucalipto se fazer presente no ms desde a década de 1970, ela não era representativa em âmbito estadual na geração de emprego e salário. Entretanto, a instalação de duas plantas de indústria de celulose na região contribuiu para dinamizar diversas atividades econômicas, dentre elas, o cultivo de eucalipto. A partir de 2013, percebe-se esse impacto, quando a atividade gerou 3.754 empregos, respondendo por 0,59\% do estoque de Ms. Em 2015, esse quantitativo alcança o montante de 4.551 empregos, representando $0,71 \%$ de todo o emprego gerado no Ms.

O quarto grupo de atividades constante nesta pesquisa está relacionado com a indústria de transformação, sendo inseridas as atividades econômicas referentes à fabricação de açúcar e de álcool.

TABELA 9 | ICN referente à atividade de fabricação de açúcar e álcool, no Ms - 2015

\begin{tabular}{|l|l|c|l|c|}
\hline \multicolumn{1}{|c|}{ ATIVIDADE } & \multicolumn{1}{|c|}{ MUNICÍPIOS } & ICN & \multicolumn{1}{c|}{ MUNICÍPIOS } & ICN \\
\hline \multirow{2}{*}{ Fabricação de Açúcar } & Angélica & 7,12 & Rio Brilhante & 3,29 \\
& Maracaju & 1,74 & & \\
\hline \multirow{2}{*}{ Fabricação de Álcool } & Bataiporã & 1,76 & Nova Alvorada & 3,89 \\
& Chapadão do Sul & 1,73 & Nova Andradina & 1,56 \\
& Dourados & 1,98 & Ponta Porã & 1,11 \\
& Fatima do Sul & 1,49 & Rio Brilhante & 2,51 \\
\hline
\end{tabular}

FONTE ELABORADO PELOS AUTORES, COM DADOS DA RAIS 2015

Ao mensurar o ICN para a atividade econômica de fabricação de açúcar, foram identificados os municípios que têm essa atividade econômica como indutora na geração de emprego (tabela 9). Nos três municípios, essa atividade é a principal geradora de emprego com destaque para Angélica onde a fabricação de açúcar é responsável por $82,5 \%$ do estoque de emprego. A segunda atividade refere-se à fabricação de álcool e, de acordo com a metodologia utilizada, foi identificado que oito municípios (tabela 9) são especializados na fabricação de álcool, ou seja, têm essa atividade como importante fonte geradora de emprego e massa salarial. 
Ao elaborar o ranking das atividades que mais geram empego para os municípios que têm especialização na atividade de fabricação de álcool, constatou-se que a atividade está entre as quatro mais importantes para os municípios, sendo que, nos municípios de Nova Alvorada e Bataiporã, ela está em primeiro lugar. Em Rio Brilhante, Ponta Porã e Chapadão, a fabricação de álcool ocupa a segunda posição.

Ficou claro que as indústrias de transformação, no caso específico, a indústria de fabricação de álcool, contribuíram para dinamizar as economias locais dos diversos municípios onde estão instaladas, por meio de geração de emprego e massa salarial, favorecendo o crescimento e o desenvolvimento regional. Tal situaçáo ocorre porque elas tendem a se instalar o mais próximo possível das fontes produtoras de matéria-prima, fazendo com que haja redução nos custos de transação, principalmente no transporte, consequentemente, poderá entregar produto com preços competitivos aos diversos mercados (ISARD, 1956).

É de fundamental importância destacar que o cálculo do ICN permitiu avaliar que, dos 79 municípios do estado de Ms, 33 têm especialização em, pelo menos, uma atividade de base agropecuária. Isso ressalta que todos os tipos de atividade são importantes para os municípios, pois geram emprego e massa salarial, além de contribuir para o fomento da economia local.

\section{Discussáo}

Conforme relatado no item "Resultados", em 2006, atividades econômicas específicas ligadas ao grupo da agropecuária respondiam por 5,29\% do emprego gerado em Mato Grosso do Sul. Já em 2015, esse percentual saltou 12,21\% do estoque de emprego no Estado. Cabe salientar, também, que funçóes ligadas à indústria de transformação referem-se à fabricação de álcool e à de açúcar, ou seja, estão intimamente ligadas às tarefas de base agropecuária, demonstrando sua contribuição para a geração de emprego.

De acordo com Figueiredo (2003), o setor primário exerce influência nos demais setores da economia. Assim, com o crescimento do setor da agropecuária, empregos e salários são gerados, e o quantitativo dessas variáveis são ainda maiores para outros setores e atividades, ou seja, o setor da agropecuária age como uma mola propulsora do crescimento econômico. Contribuindo com essa discussão, Costanzi (2004) relatou que o crescimento do emprego formal, principalmente na região Centro-Oeste, está relacionado com o crescimento do agronegócio. Reconhece-se, então, que o setor primário gera mais empregos e, por conseguinte, maior renda. $\mathrm{Na}$ verdade, pode-se afirmar que o desenvolvimento local constitui um processo econômico reativador e dinamizador da sociedade local, por meio do aproveitamento eficiente dos recursos endógenos existentes em certo território ou região, capaz de estimular e diversificar sua economia crescente, criar empregos e, assim, melhorar a qualidade de vida da comunidade. Esse processo de desenvolvimento, obviamente, é o resultado de um compromisso no qual se entende o espaço como um lugar de solidariedade ativa, que implica mudanças em grupos e indivíduos (Bungenstab, 2012; Monastério \& Cavalcante, 2011). 
A microrregiáo de Porto Murtinho e Ladário tem a atividade de criação de bovinos como um dos principais indutores no processo de geraçáo de emprego e salário, caracterizando, assim, a definição de território feita por Schneider (2004), na qual os territórios são organizadores de funçôes econômicas, onde se iniciam, desenvolvem e potencializam processos relacionais de estrutura produtiva.

Três Lagoas, abrange os municípios de Água Clara, Brasilândia, Ribas do Rio Pardo, Santa Rita do Pardo, compondo a segunda microrregião. Desses municípios, 03 apresentaram especialidade na atividade econômica de criação de bovinos (Brasilândia, Ribas do Rio Pardo, Santa Rita do Pardo), tendo como principal característica a presença de solo arenoso com média e baixa fertilidade, propiciando a criação de bovinos (SEMADE, 2015). É nessas regiôes, que têm como especialidade econômica a bovinocultura, que se concentram os maiores rebanhos, sendo que, no conjunto, chega a 4.564 .461 cabeças de gado, o que representa $21,37 \%$ de todo o estado de MS (IBGE, 2016). Face à importância dessas atividades, na geração de emprego e salário, para as duas regióes, elas poderiam ser denominadas como microrregião da pecuária.

Além disso, a presença das indústrias relacionadas com o abate de bovinos, aves e suínos é importante para o desenvolvimento econômico regional, dinamizando o comércio e a economia local mediante a geração de empregos e salários, principalmente para os municípios de pequeno porte, com população inferior a 45 mil habitantes (Schneider, 2004).

Os municípios que possuem especialização na atividade econômica do cultivo de cana-de-açúcar, com os respectivos indicadores destacaram Caarapó e Costa Rica que apresentaram ICN de 3,50 e 5,55, respectivamente. Esses dois municípios têm a atividade econômica em pauta como a principal fonte de geração de empregos e salários. Em Costa Rica, 24,37\% de todo o emprego gerado no município refere-se ao cultivo de cana e a massa salarial corresponde a 29,73\%. No município de Caarapó, a atividade do cultivo de cana de açúcar responde por 14,2\% de todo o estoque de emprego e $20,47 \%$ da massa salarial. A pesquisa evidenciou, como já comentado, que os municípios com especialização em, pelo menos, uma das atividades de base agropecuária, foram identificados por meio da mensuração do índice de concentração normalizado (ICN), identificando que, pelo menos, 33 deles têm uma das atividades de base agropecuária elencadas, constituindo-se, por isso, importante fonte na geração de emprego nos municípios de MS e, portanto, constituem-se indutores da dinamização das economias locais.

\section{Conclusáo}

O objetivo desta pesquisa foi analisar a contribuição das atividades de base agropecuária na geração de emprego formal nos municípios de Mato Grosso do Sul, com base nos dados secundários da RAIs, no período de 2006 a 2015.

Esse objetivo, evidentemente, foi alcançado, pois foi constatada uma ampliação das açóes ligadas ao setor agropecuário, proporcionando diversificação da base produtiva. Ressalta-se que, em 2005 , a economia sul-mato-grossense possuía quatro atividades de base agropecuária representativas na geração de emprego e salário 
e, em 2016, houve um aumento expressivo, aumentando para nove atividades distintas. Evidenciou-se, também, que a matriz produtiva do Ms pode contar não somente com o binômio "boi e soja”, mas também com a produção de suínos, aves, cana-de-açúcar, o eucalipto e o sistema agroindustrial que orbitam em torno desses produtos (frigoríficos de suínos e aves, fábricas de açúcar e álcool, fábrica de celulose), o que certamente potencializa a geração de empregos na regiáo.

As atividades de base agropecuária, certamente, têm gerado emprego, colaborando no aquecimento econômico dos municípios, além de serem geradoras de insumos para outros setores, constituindo-se peça-chave na engrenagem da construção do crescimento e do desenvolvimento regional. Ficou comprovado, também, que essas atividades criaram empregos e massa salarial de forma crescente, contribuindo para a dinamização das cidades, além de serem geradoras de insumos para outros setores, constituindo-se, assim, peças-chave na engrenagem da construção do desenvolvimento regional, em Mato Grosso do Sul.

Convém acrescentar que a limitação deste trabalho se concentrou no fato de apenas a variável emprego, como medida de crescimento econômico, ter sido analisada, o que evidencia a necessidade de trabalhos futuros sobre desenvolvimento, incluindo outras variáveis, como, infraestrutura, saúde, renda, diante da mudança produtiva de determinados municípios.

\section{Referências bibliográficas}

Bungenstab, D. J. (ed.). (2012). Agronegócio com sustentabilidade: A eficiência das cadeias produtivas do agronegócio em Mato Grosso do Sul. Brasília, DF: Embrapa.

Cavalcante, L. R. (2008). Produção teórica em economia regional: uma proposta de sistematização. Revista Brasileira de Estudos Regionais e Urbanos, 2(1), 9-32. https:// www.revistaaber.org.br/rberu/article/view/12/65

Companhia Nacional de Abastecimento (CONAB) (2015). Perspectivas para a agropecuária / Companhia Nacional de Abastecimento -Brasília: Conab-v 3.

Costanzi, R. N. (2004). Evolução do emprego formal no Brasil (1985-2003) e implicações para as políticas públicas de geração de emprego e renda. Texto para Discussão n. 1039. Brasília: Instituto de Pesquisa Econômica Aplicada (IPEA). http://repositorio.ipea.gov.br/ handle/11058/1875

Crocco, M. A., Galinari, R., Santos, F., Lemos, M. B. \& Simōes, R. (2006). Nova Economia, 16(2), 211-241. https://dx.doi.org/10.1590/S0103-63512006000200001.

Cruz, R. (2000). Marcos teóricos para a reflexão sobre as desigualdades regionais: uma breve revisão da literatura. RDE Revista de Desenvolvimento Econômico, 2(3), 54-66. http:// revistas.unifacs.br/index.php/rde/article/view/581

Empresa Brasileira de Pesquisa Agropecuária (Embrapa). (2008). Ministério da Agricultura, Pecuária e Abastecimento. Agricultura Tropical: Quatro décadas de inovações tecnológicas, institucionais e políticas. Vol. 1 Produção e produtividade agrícola. 
Figueiredo, M. G. (2003). Agricultura e estrutura produtiva do Estado do Mato Grosso: uma análise insumo-produto. Dissertação, Mestrado em Ciências, área de concentração: Economia Aplicada. Escola Superior de Agricultura "Luiz de Queiroz", Universidade de São Paulo, Piracicaba.

Hirschman, A. (1961 [1958]). A estratégia do desenvolvimento econômico. Rio de Janeiro: Fundo da Cultura.

Instituto Brasileiro de Geografia e Estatística (IBGE) (s/d.). Sistema IBGE de Recuperação Automática (SIDRA). https://sidra.ibge.gov.br/home/lspa/brasil.

Instituto Brasileiro de Geografia e Estatística (iвge) (2014). Produção da Pecuária Municipal - 2014. [Em línea]. https://ww2.ibge.gov.br/home/estatistica/economia/ppm/2014/ default.shtm

Isard, W. (1956). Location and space economy: a general theory relation to industrial location, market areas, land use trade and urban structure. Cambridge, MA: The MIT Press.

Krugman, P. (1998). Development, geography, and economic theory. 4th ed. Cambridge, MA: The MIT Press.

Marshall, A. (1982 [1890]). Princípios de economia. São Paulo: Abril Cultural.

Mato Grosso do Sul (2015). Plano Plurianual Estadual - PPA 2016-2019. Governo do Estado de Mato Grosso do Sul.

Mingoti, S. (2005). Análise de dados através de métodos de estatística multivariada: uma abordagem aplicada. Belo Horizonte: Universidade Federal de Minas Gerais (UFMG).

Ministério do Desenvolvimento, Indústria e Comércio Exterior (MDIC) (2016). Potencial do agronegócio é destaque na $5^{a}$ edição de Fórum Econômico Brasil - França. [Em línea]. https://bit.ly/2kpgTYR

Ministério da Agricultura, Pecuária e Abastecimento (MAPA) (2016). Notícias / 2016, o ano da ampliação de mercados para o agronegócio brasileiro. Retrospectiva 2016. https://bit. ly/2Mfjwss

Ministério do Trabalho (2015). Relação Anual de Informaçôes Sociais (RAIs). Portal do Fundo do Amparo ao Trabalhador. https://bit.ly/2nolfh6

Monastério, L. \& Cavalcante, L. R. (2011). Fundamentos do pensamento econômico regional. Em B. O. Cruz, B. A. Furtado, L. Monasterio \& Walderly Rodrigues Júnior (orgs.), Economia Regional e Urbana. Teorias e métodos com ênfase no Brasil (pp. 43-77). Brasília: Ipea. https://bit.ly/2My8kEf

Motta, F. O. (1960). Manual de localização industrial: uma tentativa de adequação da teoria à realidade. Recife: Banco do Nordeste (BN) / Escritório Técnico de Estudos Económicos do Nordeste (ETENE).

Ortega, A. C. (2008). Territórios deprimidos: desafios para as politicas de desenvolvimento rural. Campinas: Alíinea.

Perroux, F. (1977). O conceito de polo de desenvolvimento. Em J. Schwartzman (org.), Economia Regional: textos escolhidos (pp. 145-156). Belo Horizonte: Cedeplar.

Pochmann, M. (2002). O trabalho sob fogo cruzado: exclusão, desemprego e precarização no final do século (3a ed.). São Paulo: Contexto, Coleção Economia.

Santos, E. L., Braga, V., Santos, R. S. \& Braga, A. M. (2012). Desenvolvimento: Um Conceito Multidimensional. Desenvolvimento Regional em debate, 44-61. 
Schneider, S. (2004). A abordagem territorial do desenvolvimento rural e suas articulações externas. Sociologias, 6(11), 88-125. https://dx.doi.org/10.1590/S151745222004000100006

Secretaria de Estado de Meio Ambiente e Desenvolvimento Econômico (semade) (2015). Diagnóstico sócioeconômico de Mato Grosso do Sul. Campo Grande: semade / Governo do Estado de Mato Grosso do Sul. https://bit.ly/2rvIKV6

Secretaria de Estado de Meio Ambiente e Desenvolvimento Econômico (semade) (2016). Perfil estatístico de Mato Grosso do Sul. Campo Grande: SEMAde / Governo do Estado de Mato Grosso do Sul. http://www.seinfra.ms.gov.br/wp-content/uploads/sites/6/2017/06/ Perfil_Estat\%C3\%ADstico_MS_2016.pdf

Serviço Brasileiro de Apoio às Micro e Pequenas Empresas (sebrae) (2002). Subsidios para a identificação de clusters no Brasil: atividades da indústria. São Paulo: SEBrae. https://bit. ly/2ASDO6C

Silva, S. C. (1976). Teorias da localização e de desenvolvimento regional. Geografia, 1(2), 1-23. Souza, N. J. (2009). Desenvolvimento econômico. 5a ed. São Paulo: Atlas.

Thünen, J. H. (1966 [1826]). The isolated state. Nova York: Pergamon Press.

Weber, A. (1957). Theory of location of industries. 2nd ed. Chicago, Il: University of Chicago Press. 